\title{
Group's psychological potential as a condition for the effective education of foreign students in Russian university
}

\author{
Aleksey Chernyshev ${ }^{1}$, Sergei Sarychev ${ }^{1 *}$, Sergei Elizarov ${ }^{1}$, Anna Foroponova ${ }^{2}$ \\ ${ }^{1}$ Kursk State University, Chair of Psychology, 305000 Kursk, Russia \\ ${ }^{2}$ Kursk State University, Chair of Russian Language for Foreign Citizens, 305000 Kursk, \\ Russia
}

\begin{abstract}
The paper discusses the results of an empirical study of the influence of the socio-psychological characteristics of academic student group upon the success of the educational activities of foreign students in Russian universities using the example of students studying in universities of the city of Kursk. The dependence between the nature of the leading attitudes towards educational and professional activities of foreign students at the university is shown on the level of development of the student academic group, which also acts as a subject of psychological assistance to foreign students who find themselves in new ethnocultural conditions.
\end{abstract}

The process of internationalization of higher education in modern Russia raises a number of socio-psychological problems associated with the creation of favorable conditions for foreign students to increase the success of training and adaptation in new for them living conditions.

As it was established in numerous studies, the determination of learning success is systemic in nature, including both personality and group components. In addition, in a number of works it is noted that the creation in student groups of the highest level of development of the social microsphere is an important condition for the formation of the personality of a future professional [1]. In this regard, it is important that the success of the student's personality formation is determined by the level of organization of the academic student group, its values, conditions and socio-psychological settings, as well as such subjective characteristics of the group as its morality, business and creative qualities.

The aim of the investigation was to study the socio-psychological mechanisms of the influence of an academic student group on the success of the educational activities of foreign students. The hypothesis of the study was the assumption that it is possible for foreign students studying at a Russian university to have a value-semantic attitude towards a group as a subject of psychological assistance in a social environment for becoming an individual and a professional. The study involved foreign and Russian students learning at universities in the city of Kursk.

\footnotetext{
*Corresponding author: kursk-psychol@yandex.ru
} 
The theoretical basis of the study was the concept of "student involvement in the group's joint activity" which we understand as coherence with the socio-psychological characteristics of the group (goals, values, norms, roles, etc.), and their willingness to develop and protect them [2]. This gave us the opportunity to empirically determine the differences in the severity of attitudes and their hierarchical position (rank) in groups of different levels of development, in connection with which we classified the studied student groups by analogy with the typology of groups in the parametric theory of small groups and groups depending on the level their socio-psychological maturity: highly developed groups (collectives) close to highly developed groups - autonomy groups; sufficiently developed (middle level) - cooperatives and insufficiently developed - associations [6]. The study found that the prevailing groups were of three types: a sufficiently high level, average level and insufficient level. Highly developed groups (collectives) turned out to be about five percent.

As a result of the study, empirical data were obtained on the influence of group typology on the structure of educational motivation. First of all, the features of the structure of educational motivation were established depending on the level of development of the group according to the following criteria:

- completeness of coverage of all motives (system of many motives);

- priority (severity) of positive motives in the overall structure.

It was found that the optimal motivation is typical for student of autonomy groups in connection with the inherent more pronounced completeness (system of many motives) of student motivations to study, as well as the breadth of positive motives compared with cooperative groups and associations groups.

The study of the influence of the group on the sustainability of professional choice motivation and success motivation among foreign students from different cultures allowed us to establish that the highest professional choice sustainability is typical for students from Southeast Asia, while students from Western Europe and North America show rather low sustainability indicators. It is likely that this phenomenon is associated with the possibility of a fairly painless change of profession in the highly developed countries Western Europe and North America and the preservation of stability in the chosen profession in developing countries and partly in Russia.

Describing the features of motivation to achieve the status of a successful person, it is necessary to note the undoubted leadership of Russian students, while for foreign students, regardless of ethnicity, motivation of this type was noticeably lower in all types of student groups. We attribute this to the Russian mentality, in which the status of a successful individual, especially thanks to the efforts of modern Russian media, is gaining more and more popularity. At the same time, as A.V. Yurevich emphasizes, the content of this phenomenon is changing markedly: since people who were able to be beneficial were previously called a successful person, and nowadays, a successful person is increasingly associated with fame and wealth [3].

The comparative study of the motivation of foreign and Russian students showed that Russian students are characterized by pronounced system of many motives of student's educational activity: almost all the motives of the structure under study (internal and external motives) were part of the structure of student motivation. Moreover, in the structure of the hierarchy, internal motives occupied higher places than external ones. In addition, there is a differentiation among internal motives, for example, the motive "I study to become a highly qualified specialist" was put above the motives "acquisition of deep and lasting knowledge, obtaining intellectual satisfaction, successfully continue training in the next course", etc. External motives turned out to be less pronounced: "obtaining a diploma, keeping up with fellow students, fulfilling pedagogical requirements, obtaining parental approval", etc. 
Pragmatic orientation was typical for foreign students, especially for representatives of Western Europe, which manifested itself in the concentration of motivation around a small number of motives of a mixed type and ignoring (omission) of other motives. In particular, Western European students used only about half of the motives proposed by us in the questionnaire; students from China, India, Africa and South America turned out to be slightly larger.

We also established a sufficiently detailed, organically connected with the tasks of vocational training, structure of the image of the future as the degree of recognition by foreign students of the distant learning goals in the framework of personal success and professional career growth in their recent future (5-10 years after graduation). Since they reflect the main personal and professional potentials laid down during the period of study at the university, the attitude towards the degree of their awareness and acceptance can be considered as the determination of successful education.

The leading role in the structure of the "image of the future" belongs to the readiness to preserve the chosen profession in future professional activity. This component takes the first place in expressions of students of all types of groups. The second place is consistently put forward by the attitude towards career advancement in professional activities and also in groups of all levels of development. Foreign students not only see themselves as specialists in their chosen profession, but as well-deserved, recognized professionals in society. This is eloquently evidenced by statements like: "... I am the best doctor in my country, ... a talented specialist, ... successful in my career of choice, ... one of the best surgeons in the country", etc. This orientation is typical for a significant part of foreign students.

Analyzing the state of the structure of the image of the future in the representations of students from groups of different levels of development, it should be noted that the influence of the "group effect" on the phenomenon turned out to be balanced. We explain this situation by a stronger influence on students' social perceptions of the ultimate goals of education compared with a group of a number of macro-social factors - public consciousness, advertising, etc. We can assume that our results are consistent with B.D. Parygin's data concerning the direct influence of some social institutions on the individual in comparison with group influence [4].

The results of the study also allowed us to establish that the academic study group for foreign students also acts as a subject of psychological assistance with a fairly productive structure. This structure includes the following components:

- psycho-emotional support of the personality of students;

- stimulation of a responsible attitude to education;

- counseling of foreign students in mastering difficult sections and topics;

- providing foreign students with the necessary teaching materials [5].

The significance of each component in the overall structure is presented differently in the polar groups depending on the level of their development [6]. This is especially noticeable in groups of high and medium level of development.

In particular, the priority of the component "stimulating responsible attitude to study" in high-level development groups reflects the prevailing group consciousness regarding the adoption of educational and professional motives and goals as a leading personally significant and socially significant value, when a favorable business atmosphere in the group ensures the effectiveness of advisory assistance, at the same time the need for psycho-emotional support is reduced, as the first two components increase academic success and reduce the failures that bring traumatic experiences.

The group's attitude toward mutual enrichment with various methodological materials, the diversity range of which is currently so rich that individual finds of effective 
methodological tools are becoming very useful for the rest of the group, is also quite pronounced.

In the middle-level groups, the leading component is the "advisory assistance" component, which we associate with unfolded group consciousness regarding the adoption of educational and professional goals and, as a result, the growing role of individual mutual assistance. A decrease in group motivation to study leads to insufficient learning of more students and, as a result, the need for more frequent recourse to help. Trends in more pronounced learning failures in such groups are associated with a large number of psychological injuries, which potentially increases the need for psycho-emotional support.

The weakening of the component "stimulating by the group a responsible attitude towards learning" of its participants in groups of this category is consistent with A.L. Zhuravlev's data that members of youth groups can weaken business relationships for the sake of preserving accepted emotional ties, which leads to a shift in the main, in this case, educational goals for which groups are created, for secondary goals - satisfaction with warm friendships [7].

Common to groups of all types is the low severity of "the desire to realize their personal potential in the group." We attribute this to the multifaceted inclusion of foreign students (according to the plans for educational work of universities with foreign students) in cultural events of various types at faculty, university and other levels. At the same time, the most appropriate in this situation should still be considered the optimal distribution of student activity in all social systems, and especially in their academic group.

The growing role of the group as a subject of psychological assistance is also caused by problems in the social well-being of foreign students studying in Russian universities. The results show a pronounced difference in the state of social well-being, including both positive and negative components in the groups of high and underdevelopment.

The source of the positive image of Self is most often a complex of reasons, including such positive personal qualities as responsibility, hard work, interest (love) to study, mental abilities, as well as satisfaction with one's position in the group and, of course, with successes in studies.

Negative social well-being as a feeling of discomfort is also determined by personal and group factors of only the opposite quality, however, tense or even conflicting relations between students and the group prevail in this area, as the following judgments say: "... I am sorry that I do not feel confident, therefore some talk when I answer, so I'm embarrassed to answer, ... I won't study well because the group considers me incapable."

Thus, our study allows us to determine the psychological potential of the academic study group as an important condition for the effective education of foreign students at a Russian university, as a personally significant and socially valuable organization in adapting to their new culture and increasing the success of their educational activities.

The effective inclusion of academic groups of foreign students in the system of diverse social organizations as a subject of joint activity can lead to an increase in the level of business, creative, moral qualities and orientation of activity of both the student groups themselves and the foreign students that make them up.

\section{References}

1. M.I. Dyachenko, L.A. Kandybovich, S.L. Kandybovich Psikhologiya vysshey shkoly (Belarusian State University, Minsk, 1981)

2. S.G. Elizarov, Effektivnost' lichnosti, gruppy i organizatsii: problemy, dostizheniya i perspektivy, 255-258 (2017)

3. A.V. Yurevich, Yaroslavskiy pedagogicheskiy vestnik. 4. 168-179 (2018) 
4. B.D. Parygin Sotsial'naya psikhologiya. problemy metodologii, istorii i teorii (St. Petersburg Humanitarian University of Trade Unions, St. Petersburg, 1999)

5. A.A. Foroponova, Ot istokov $\mathrm{k}$ sovremennosti. 130 let organizatsii psikhologicheskogo obshchestva pri Moskovskom universitete.1, 390-392 (2015)

6. A.S. Chernyshev, S.V. Sarychev, N.N. Greben'kov, Scientists notes. Electronic scientific journal of Kursk State University. 11, 1-12 (2019)

7. A.L. Zhuravlev, Psikhologicheskiy zhurnal. 30 (5),72-80 (2009) 